\title{
Design and Fabrication of Duplexer for GSM900 Band Applications
}

\author{
Suresha L, Sunil Kn, \\ Umesh Kumar A \\ Shashi Kumar K \\ Dept. Of Telecommunication \\ R.V.C.E \\ Bangalore, India
}

\author{
R K Manjunath \\ Dept. Of Telecommunication \\ R.V.C.E \\ Bangalore, India
}

\author{
Dr.Nagamani K \\ Dept. Of \\ Telecommunication \\ R.V.C.E \\ Bangalore, India
}

\begin{abstract}
This paper presents the design technique and simulation of Duplexer for GSM 900 band applications using microstrip technology.Two band pass filters with unequal impedance are designed. One filter with the 890-915MHz band and other filter with the 935-960MHz. Then these two filters are combined together in parallel to act as a duplexer with the uplink frequency band as 890$915 \mathrm{MHz}$ and downlink frequency band as $935-960 \mathrm{MHz}$. The simulation is done using ADS software. Next, tuning and optimization are applied to achieve the low insertion loss. The proposed duplexer is a proof of concept for realizing duplexer functions using microstrip technology. In general, duplexers are built using high quality factor cavity filters. However, to prove the concept, duplexer is fabricated using FR-4 material which is readily available in India.
\end{abstract}

Keywords: Advanced Design System (ADS), Bandpass Filter (BPF), Fractional Bandwidth (FBW)

\section{INTRODUCTION}

The duplexer is a device that isolates the receiver from the transmitter while permitting them to share a common antenna. The duplexer is often the key component that allows two way radios to operate in a full duplex manner. An ideal duplexer provides perfect isolation with no insertion loss to and from the antenna. A conventional duplexer is a three-port device and normally consists of two band pass filters and impedance transforming circuit to allow both filtered to connect to a common antenna port. [4,6]

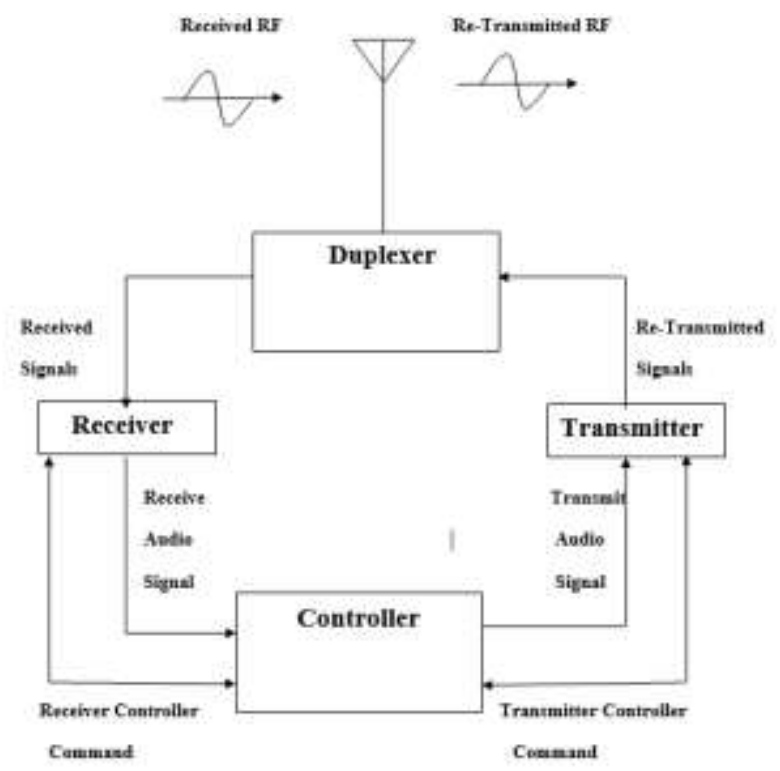

Figure 1:Block diagram illustrating the working of duplexer.
The working of duplexer is as shown in the figure 1. During transmission, signals from controller are transmitted to antenna through transmitter band pass filter which rejects the signals having frequency range other than $890-915 \mathrm{MHz}$.

During reception the signals received by antenna are passed to controller through receiver band pass filter which rejects signals having frequency range other than $935-960 \mathrm{MHz}$.

\subsection{Band pass filter:}

Filters are indispensable devices in many systems and applications including wireless broadband, mobile, satellite communications, radar, navigation, sensing and other systems. With the development of these systems, mostly induced by great commercial interests, limited electromagnetic spectrum has to be shared among more and more systems. Thus, there is an increasing demand for RF, microwave and millimeter wave filters with more stringent requirements.These filters are employed in various systems to select or confine signals with specified spectral limits. Electronic filters are circuits that have signal processing functions. i.e. they transform an input signal to obtain an output signal with the required characteristics. In the frequency domain filters are used to reject unwanted signal frequencies and to pass signals of desired frequencies.

A bandpass filter only passes the frequencies within a certain desired band and attenuates others signals whose frequencies are either below a lower cut-off frequency or above an upper cut-off frequency. The range of frequencies that a bandpass filter allows to pass through is referred as passband. A typical bandpass filter can be obtained by combining a low-pass filter and a high-pass filter or applying conventional low pass to bandpass transformation.A band pass filter is an electronic circuit which allows the signals with the desired frequency band and supresses the signals out of that band. 


\subsection{Microstrip}

Microstrip is an electrical transmission line which can be fabricated using printed circuit board technology and is used to convey microwave frequency signals[1][7]. It consists of conducting strip separated from a ground plane by a dielectric layer known as substrate as shown in figure 2 .

Microstrip line is used to carry electromagnetic waves or microwave frequency signals. Microstrip lines will have low to high radiation, will support 20 to $120 \mathrm{ohm}$ impedance, supports Q factor of 250 .

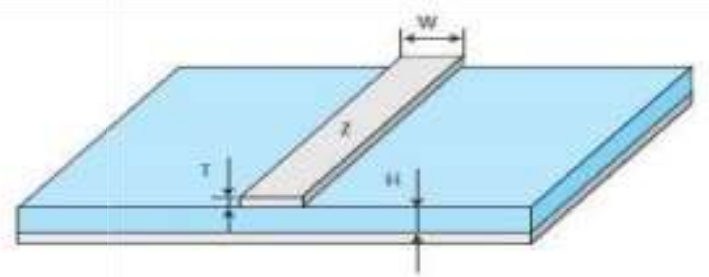

Figure 2: Microstrip structure

Microwave components such as Antennas, Couplers, Filters, Power dividers etc. can be formed from microstrip, the entire device existing as the pattern of metallization on the substrate.

Microstrip is much less expensive than traditional waveguide technology, as well as being far lighter and more compact.

\subsection{ADS Software}

Advanced Design system (ADS) is an automation software produced by Agilent EEsof EDA, a unit of Agilent technologies. It provides an integral design environment to designers of RF electronic products such as mobile phones, pagers, wireless networks, satellite communication etc.

Agilent ADS supports every step of the design process like layout, simulation, frequency-domain and time-domain circuit simulation and electromagnetic field simulation allowing engineers to full characterize and optimize RF design without changing the tools.

\section{DESIGN FLOW}

Two chebyshev bandpass filters are designed with the frequency bands $890-915 \mathrm{MHz}$ and $935-960 \mathrm{MHz}$. The pass band ripple is taken as $0.5 \mathrm{~dB}$.Insertion loss and return loss are required to be maximum of $2 \mathrm{~dB}$ and minimum of $10 \mathrm{~dB}$ respectively.

The job in designing any type of filter is to calculate its order. So the order of the filters are calculated by using the below equation

$\mathrm{N} \geq \frac{L a+L r+6}{20 \log _{10}\left(S+\sqrt{\left(S^{2}+1\right)}\right)}=6$.

Where, $\mathrm{N}$ is the order of the filter

$\mathrm{La}=$ Attenuation in stop band

$\mathrm{Lr}=$ Ripple in pass band $=0.5$

$\mathrm{S}=$ Selectivity factor of the filter

$=\frac{\text { Stop band frequecy }}{\text { Pass band frequency }} \geq 1$

The chebyshev filter coefficients are obtained from the table 1 .
Table.1:Chebyshev filter coefficients with $0.5 \mathrm{~dB}$ ripple.

\begin{tabular}{|c|c|c|c|c|c|c|c|c|c|c|c|}
\hline N & $\mathrm{g} 1$ & g2 & $g 3$ & $g 4$ & $g 5$ & $g 6$ & g7 & $g 8$ & g9 & $\mathrm{g} 10$ & g11 \\
\hline 1 & 0.6986 & 1.0000 & & & & & & & & & \\
\hline 2 & 1.4029 & 0.7071 & 19841 & & & & & & & & \\
\hline 3 & 1.5963 & 10967 & 15963 & 10000 & & & & & & & \\
\hline 4 & 1.6703 & 1.1926 & 2.3651 & 0.8419 & 19841 & & & & & & \\
\hline 5 & 1.7058 & 1.2296 & 2.5408 & 12296 & 17058 & 10000 & & & & & \\
\hline 6 & 1.7254 & 1.2479 & 26054 & 13137 & 24758 & 0.8695 & 1.9841 & & & & \\
\hline 7 & 1.7372 & 1.2583 & 26381 & 13444 & 26381 & 12583 & 1.7372 & 1.0000 & & & \\
\hline 8 & 1.7451 & 1.2647 & 26564 & 13590 & 26964 & 13389 & 2.5093 & 0.8796 & 1.9841 & & \\
\hline 9 & 1.7504 & 1.2690 & 26678 & 13673 & 27939 & 13673 & 2.6578 & 1.2690 & 1.7504 & 1.0000 & \\
\hline 10 & 1.7543 & 1.2721 & 2.6754 & 13725 & 27392 & 13805 & 2.7231 & 1.3485 & 2.5239 & 0.8842 & 1.9841 \\
\hline
\end{tabular}

From the table chebyshev filter coefficients for low pass filter with order $\mathrm{N}=6$ are,

$\mathrm{g} 0=1, \mathrm{~g} 1=1.7254, \mathrm{~g} 2=1.2479, \mathrm{~g} 3=2.6064, \mathrm{~g} 4=1.3137, \mathrm{~g} 5=2.4758$,

g6 $=0.8696, \mathrm{~g} 7=1.9841$.

If order of the filter is $\mathrm{N}$, then the microstrip coupled line filter will have $\mathrm{N}+1$ coupled lines. So that here the number of microstrip coupled lines in both the filters will be 7 .

To design the microstrip coupled line band pass filters,the admittance, odd and even mode excitation line impedances of each coupled lines are to be calculated. These parameters are calculated by using the below equations.

$$
\mathrm{J}_{01}=\frac{1}{\mathrm{Z}_{\mathrm{O}}} \times \sqrt{\left(\frac{\pi}{2} \times \frac{\mathrm{FBW}}{\mathrm{g}_{0} \mathrm{~g}_{1}}\right)} \ldots \ldots \ldots \ldots . . .2
$$

$$
\begin{aligned}
& \mathrm{J}_{\mathrm{i}, \mathrm{i}+1}=\frac{1}{\mathrm{Z}_{\mathrm{O}}} \times \frac{\pi}{2} \times \mathrm{FBW} \sqrt{\left(\frac{1}{\mathrm{~g}_{\mathrm{i}} \mathrm{g}_{\mathrm{i}+1}}\right) \ldots \ldots \ldots . .3} \\
& \mathrm{~J}_{\mathrm{n}, \mathrm{n}+1}=\frac{1}{\mathrm{Z}_{\mathrm{O}}} \times \sqrt{\left(\frac{\pi}{2} \times \frac{\mathrm{FBW}}{\mathrm{g}_{\mathrm{n}} \mathrm{g}_{\mathrm{n}+1}}\right)} \ldots \ldots \ldots \ldots . .4
\end{aligned}
$$

Where,J - Admittance

$\mathrm{Z}_{\mathrm{O}}=50 \mathrm{Ohm}$;

$\mathrm{FBW}=\frac{\boldsymbol{\omega}_{2}-\boldsymbol{\omega}_{1}}{\boldsymbol{\omega}_{0}}$

The admittance of each microstrip coupled lines of both the filters are calculated by using the equations $2-4$.

The above calculated admittance values are used to obtain the odd and even mode line impedances using below equations:

$$
\begin{gathered}
\mathrm{Z}_{\mathrm{oe}}=\mathrm{Z}_{\mathrm{O}}\left(1+\mathrm{Z}_{\mathrm{O}} \mathrm{J}+\left(\mathrm{Z}_{\mathrm{O}} J\right)^{2}\right) \ldots \ldots \ldots \ldots . .5 \\
\mathrm{Z}_{\mathrm{oo}}=\mathrm{Z}_{\mathrm{O}}\left(1-\mathrm{Z}_{\mathrm{O}} \mathrm{J}+\left(\mathrm{Z}_{\mathrm{O}} J\right)^{2}\right) \ldots \ldots \ldots \ldots 6
\end{gathered}
$$


The odd and even mode line impedance values will be substituted in Linecalc tool of ADS.At this point we need to decide the type of substrate to be used in fabrication of designed filters. So here we have taken the FR-4 substrate. The specifications of FR-4 substrate are tabulated in the table 2 .

Table 2: FR-4 substrate specifications

\begin{tabular}{|l|l|}
\hline Thickness & $35 \mathrm{um}$ \\
\hline Height & $1.6 \mathrm{~mm}$ \\
\hline Dielectric constant, $\boldsymbol{\varepsilon r}$ & 4.6 \\
\hline
\end{tabular}

The admittance,odd and even mode line impedances for 890$915 \mathrm{MHz}$ uplink band pass filter are tabulated in the table 3 .

Table 3: Admittance, Zoe Zoo values for uplink filter

\begin{tabular}{|l|l|l|l|}
\hline MCLIN & Admittance(Ohms) & Zoe(ohms) & Zoo(ohms) \\
\hline MCLIN 1 & 0.173732555 & 60.1957 & 42.8225 \\
\hline MCLIN 2 & 0.035490933 & 51.8375 & 48.2884 \\
\hline MCLIN 3 & 0.028876315 & 60.1957 & 42.8225 \\
\hline MCLIN 4 & 0.028143854 & 51.4467 & 48.6324 \\
\hline MCLIN 5 & 0.028876618 & 51.4855 & 48.5978 \\
\hline MCLIN 6 & 0.035492342 & 51.8376 & 48.2883 \\
\hline MCLIN 7 & 0.173733896 & 60.1958 & 42.8224 \\
\hline
\end{tabular}

The admittance, odd and even mode line impedances for 935$960 \mathrm{MHz}$ downlink band pass filter are tabulated in the table 4 .

Table 4: Admittance, Zoe Zoo values for down link filter

\begin{tabular}{|l|l|l|l|}
\hline MCLIN & Admittance(Ohms) & Zoe(ohms) & Zoo(ohms) \\
\hline MCLIN 1 & 0.173732555 & 59.9210 & 42.9542 \\
\hline MCLIN 2 & 0.033809354 & 51.7476 & 48.3666 \\
\hline MCLIN 3 & 0.027508141 & 51.4132 & 48.6624 \\
\hline MCLIN 4 & 0.026810383 & 51.3764 & 48.6954 \\
\hline MCLIN 5 & 0.027508428 & 51.4132 & 48.6624 \\
\hline MCLIN 6 & 0.03810696 & 51.9779 & 48.1672 \\
\hline MCLIN 7 & 0.169568152 & 59.9160 & 42.9592 \\
\hline
\end{tabular}

The Width (W),length (L) and $\operatorname{Spacing}(\mathrm{S})$ of microstrip conductor calculated by using Linecalc tool are tabulated in the table 5 and 6.

Table 5: Width, Spacing andLength of uplink filter

\begin{tabular}{|l|l|l|l|}
\hline MCLIN & Width $(\mathrm{mm})$ & Spacing(mm) & Length(mm) \\
\hline MCLIN 1 & 2.7354 & 0.7 & 45.1944 \\
\hline MCLIN 2 & 2.1371 & 2.5206 & 43.3990 \\
\hline MCLIN 3 & 1.9955 & 4.3427 & 44.7556 \\
\hline MCLIN 4 & 4.0815 & 5.4698 & 44.7577 \\
\hline MCLIN 5 & 2.3382 & 6.9602 & 44.7556 \\
\hline MCLIN 6 & 2.8274 & 4.4069 & 45.2838 \\
\hline MCLIN 7 & 1.7816 & 0.3 & 45.6463 \\
\hline
\end{tabular}

Table 6: Width, Spacing and Length of downlink filter

\begin{tabular}{|l|l|l|l|}
\hline MCLIN & Width $(\mathrm{mm})$ & Spacing $(\mathrm{mm})$ & Length(mm) \\
\hline MCLIN 1 & 2.4757 & 1.029 & 43.0272 \\
\hline MCLIN 2 & 2.9619 & 5.2224 & 42.618 \\
\hline MCLIN 3 & 2.9749 & 6.4583 & 42.6326 \\
\hline MCLIN 4 & 3.0955 & 6.1750 & 42.6346 \\
\hline MCLIN 5 & 2.6228 & 6.3106 & 42.6326 \\
\hline MCLIN 6 & 2.9051 & 4.5305 & 42.6100 \\
\hline MCLIN 7 & 1.3462 & 0.7309 & 43.4570 \\
\hline
\end{tabular}

\section{IMPLEMENTATION IN ADS}

As a final step, the coupled line band pass filters are designed in the ADS simulation software environment. It accepts filter parameters and produces physical dimensions of the filter layout and a simulation of the filter response.[2]

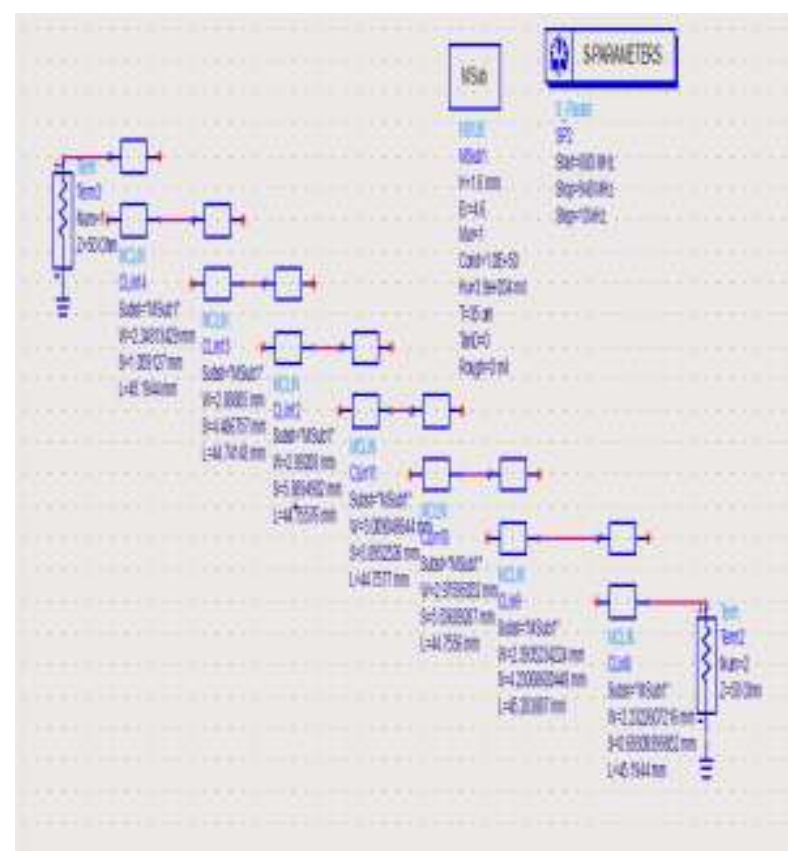

Figure 3: Schematic of uplink band pass filter

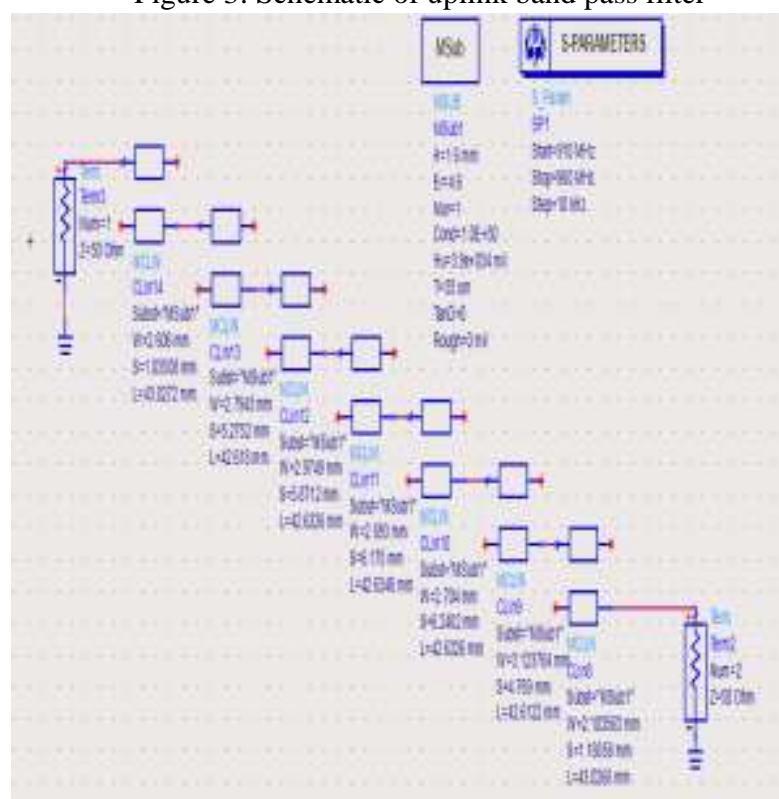

Figure 4: Schematic of downlink band pass filter

The figures 3 and 4 shows the ADS schematics of uplink (890$915 \mathrm{MHz})$ and downlink $(935-960 \mathrm{MHz})$ respectively. Both the filters are designed with the unequal impedance condition such that the impedance at the input and output of each filter are 50 ohms and 100 ohms respectively.

To design a duplexer, these two band pass filters are combined in parallel. There are different approaches to combine the BPF's to 
make a duplexer. One among that is, by using the power divider. When a power divider is used, there will be a $3 \mathrm{~dB}$ loss occurs. So that, here we have used a novel approach of 2 unequal impedance filters combined in parallel without a power divider. As a result, net impedance of parallel combined filters will be 50 ohms at all the 3 ports. So that this acts as a DUPLEXER as shown in figure 5 .

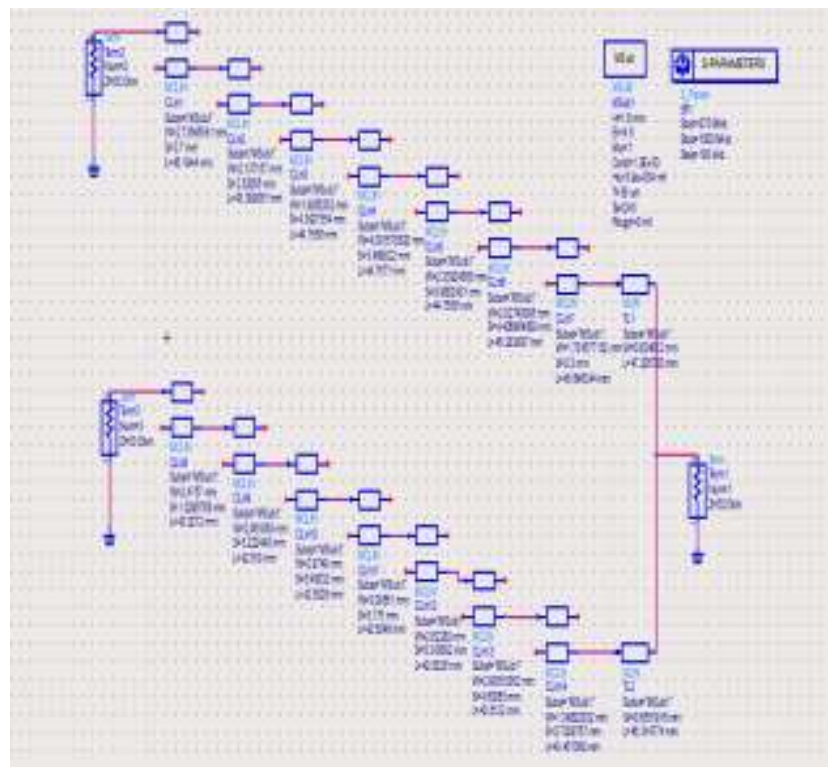

Figure 5: Schematic of Duplexer

\subsection{Simulation}

Uplink (890-915MHz) response:
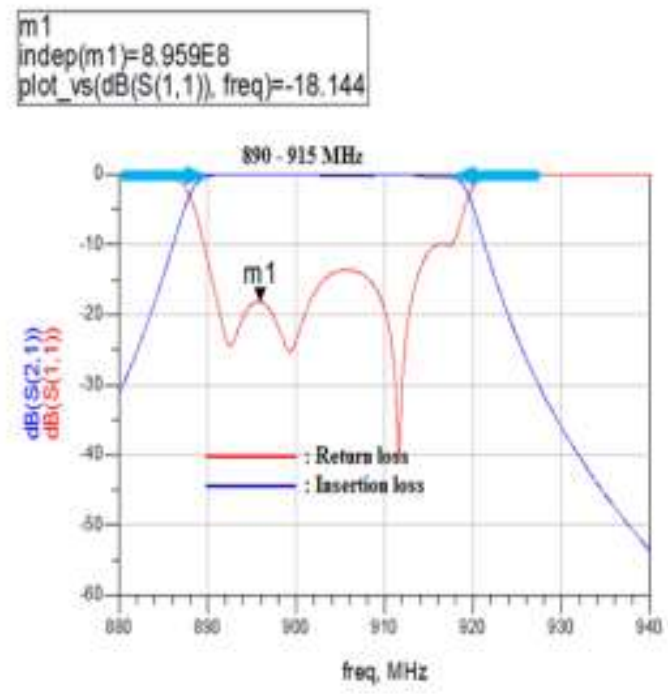

Figure 6: Response of uplink band pass filter

The figure 6 shows the response of uplink band pass filter. The filter passes the signal with the band $890-915 \mathrm{MHz}$, has the ripple less than $-1 \mathrm{~dB}$ and return loss $<-10 \mathrm{~dB}$.

Downlink (935-960MHz) response:
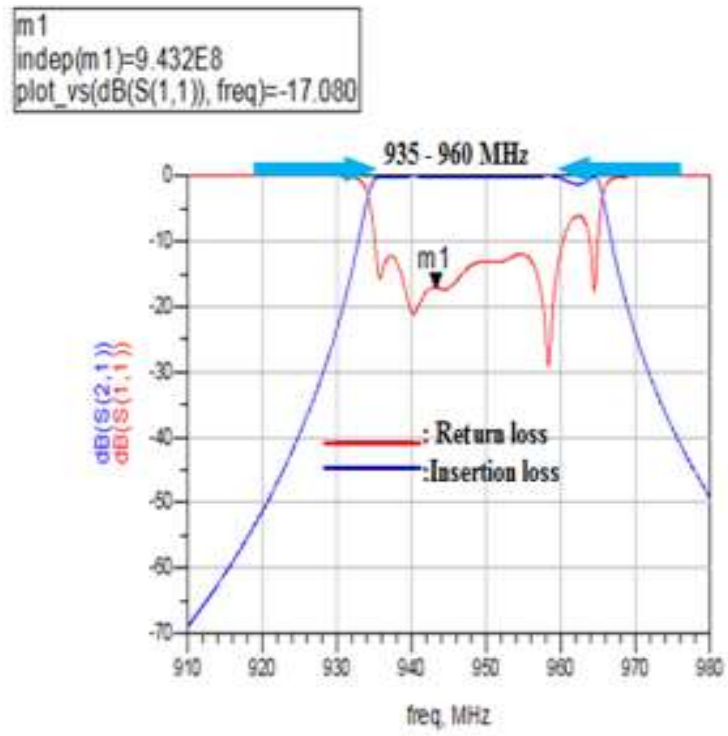

Figure 7: Response of downlink band pass filter

The figure 7 shows the response of downlink band pass filter. The filter passes the signal with the band $935-960 \mathrm{MHz}$, has the ripple less than $-1 \mathrm{~dB}$ and return loss $<-10 \mathrm{~dB}$.

\section{Duplexer response:}

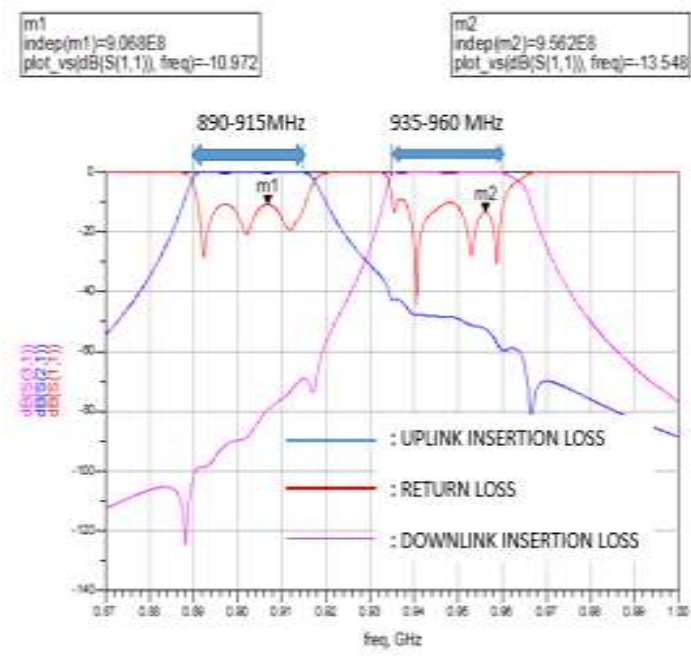

Figure 8: Response of Duplexer

The figure 8 shows the response of duplexer in which the transmitter has the band $890-915 \mathrm{MHz}$ and receiver has the band 935-960MHz. High isolation between transmitter and receiver is achieved .The return loss and ripple is obtained as less than $10 \mathrm{~dB}$ and $-0.5 \mathrm{~dB}$ respectively.

The Layout of combined microstrip coupled line band pass filter of un-equal impedance (DUPLEXER) for 890-915 MHz and $935-960 \mathrm{MHz}$ band is shown in the figure 9 . 


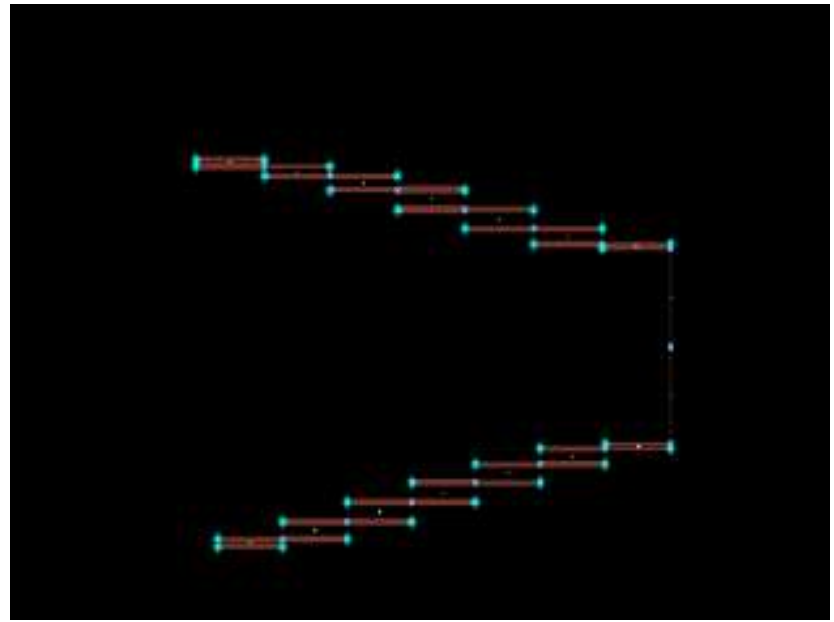

Figure 9: Layout of DUPLEXER

\subsection{Fabrication and Tested Results}

The designed duplexer is fabricated by using the flame retardant -4 (FR_4) substrate which is readily available in india. Generally, the FR-4 material has $0.3 \mathrm{~dB}$ loss per $10 \mathrm{~mm}$. So that the large length designs fabricated using FR-4 materials results in high insertion loss.

The image of the fabricated duplexer is shown below.

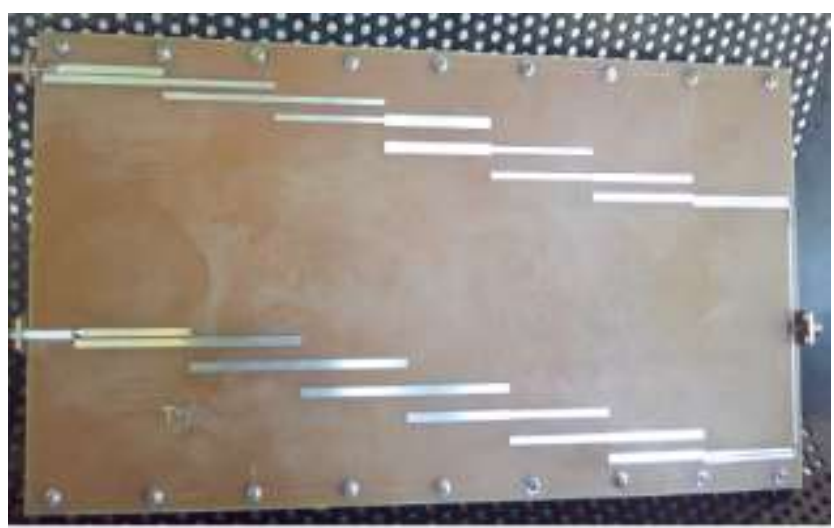

Figure 10: Fabricated Duplexer

Tested values of the duplexer are tabulated in the table7and 8 .

Table 7: Uplink tested results

\begin{tabular}{|l|l|l|l|}
\hline Parameter & $\begin{array}{l}\text { Lower } \\
\text { Frequency } \\
(890 \mathrm{MHz})\end{array}$ & $\begin{array}{l}\text { Upper } \\
\text { Frequency } \\
(915 \mathrm{MHz})\end{array}$ & $\begin{array}{l}\text { Centre } \\
\text { frequency } \\
(902.6 \mathrm{MHz})\end{array}$ \\
\hline S21 & $-32.26 \mathrm{~dB}$ & $-31.16 \mathrm{~dB}$ & $-23.955 \mathrm{~dB}$ \\
\hline S11 & $-5.34 \mathrm{~dB}$ & $-9.663 \mathrm{~dB}$ & $-12.073 \mathrm{~dB}$ \\
\hline
\end{tabular}

Table 8: Downlink tested results

\begin{tabular}{|l|l|l|l|}
\hline Parameter & $\begin{array}{l}\text { Lower } \\
\text { Frequency } \\
(935 \mathrm{MHz})\end{array}$ & $\begin{array}{l}\text { Upper } \\
\text { Frequency } \\
(960 \mathrm{MHz})\end{array}$ & $\begin{array}{l}\text { Centre } \\
\text { frequency } \\
(947.4 \mathrm{MHz})\end{array}$ \\
\hline S21 & $-41.781 \mathrm{~dB}$ & $--30.6 \mathrm{~dB}$ & $--31.621 \mathrm{~dB}$ \\
\hline S11 & $-4 . .677 \mathrm{~dB}$ & $-8.616 \mathrm{~dB}$ & $-8.354 \mathrm{~dB}$ \\
\hline
\end{tabular}

\section{CONCLUSION}

The designed duplexer is a proof of concept for realizing duplexer function using microstrip technology. In general, duplexers are built using high quality factor $(\mathrm{Q})$ cavity filters. However, to prove the concept, Duplexer is fabricated using FR-4 material which is readily available in INDIA.

The 'Q' achievable in microstrip technique is 100 times less than the cavities. Further FR-4 material is highly lossive for long transmission length like parallel coupled filter, where length is more than $300 \mathrm{~mm}$. Such large lengths result in high insertion loss of the order of 24 to $30 \mathrm{~dB}$. Since tangent factor of FR-4 is 100 times less than RT duroid material.

\section{FUTURE SCOPE}

For the duplexer realization, the isolation required is around $60 \mathrm{~dB}$. However recently less than $60 \mathrm{~dB}$ is also being used. In this paper, an attempt is made to build the duplexer using microstrip technology at low frequencies in GSM band.

In future the activities carried out in the proposed paper may be taken as basis and improve upon the design by using different materials for realizing high isolation between transmitter and receiver.

\section{REFERENCES}

1. Runqi Zhang, Lei Zhu, "Synthesis and Design of Dual- Wideband Bandpass Filters with Internally Coupled Microstrip Lines", IET Microwave Antennas Propagation, 2014, Vol.8, Iss.8, PP.556563.

2. Shreyasi Srivatsava, R.K.Manjunath, P.Shanthi, "Design, Simulation and fabrication of a Microstrip Bandpass Filter", International Journal of Science and Engineering Applications, Vol.3, Issue-5, 2014.

3. Chang Chen, Rongguo Zhou, "Design of Dual-Band Microwave Duplexers", Electronic letters, Vol.50, No.3, pp.219-221, 30 January 2014.

4. Wei Qiang, Huang Ying, "Design Method of X Band Co-axial Duplexer", IEEE Conference, Published Year: 2012, ISBN No. 978-1-4673-2185-3/12.

5. S. Srinath, "Design of $4^{\text {th }}$ Order Parallel Coupled Microstrip Bandpass Filter at Dual Frequencies of $1.8 \mathrm{GHz}$ and $2.4 \mathrm{GHz}$ for Wireless Application", International Journal of Innovative Research in Computer and Communication Engineering, Vol.2 Issue-6, June 2014.

6. M.Latrach, H.Bennis, "Microstrip Triangular Loop resonator Duplexer", International Journal of Computer and Communication Engineering, Vol.2, No.4, July 2013.

7. Ching-Wen Tang, Po-Hsien Wu, "Design of Wide Pass band/Stop band Microstrip Bandpass Filters with Stepped Coupled Lines",IEEE Transactions on Microwave Theory and Techniques, Vol.61.No.3, March 2013. 